\title{
PROBLEMÁTICA PSICOSOCIAL Y SOCIECONÓMICA COMO CONSECUENCIA DEL CONFLICTO ARMADO EN EL DEPARTAMENTO DE CÓRDOBA EN COLOMBIA
}

\author{
Victor Negrete Barrera \\ Centro de Estudios Sociales y Políticos, Universidad del Sinú, Montería - Colombia
}

\begin{abstract}
Armed conflict in Colombia has had a variety of psycho-social and socio-economic consequences. This paper addresses some of these consequences in the department of Córdoba. Consequences analyzed are the displacement phenomena, homicides indexes, land ownership concentration, economics, demobilization and the rearmament observed in several groups and conditions at the so-called location zone. Results show that while some data are promising, intervention from different disciplines is necessary in order to solve the region's problems.
\end{abstract}

Keywords: Conflict, psychosocial, displacement, economy.

\section{RESUMEN}

El conflicto armado en Colombia ha tenido consecuencias psicosociales y socioeconómicas de diversos órdenes, en este trabajo se describen algunas de ellas en el departamento de Córdoba. Las consecuencias analizadas son el fenómeno del desplazamiento, los índicadores de homicidios, la distribución de la tierra, la economía, la desmovilización y el rearme que se está produciendo en algunos grupos y el estado de la denominada zona de ubicación. Se concluye que aunque existen datos esperanzadores, todavía es necesaria una intervención desde diferentes disciplinas para solucionar los problemas existentes en la región.

Palabras Clave: conflicto, psicosocial, desplazamiento, economía.

Córdoba es un departamento de Colombia situado al sur de la Costa Caribe, su área es de 25.020 kilómetros cuadrados y su población de 1.462.909 habitantes, la mitad de los cuales viven en el área rural. La actividad económica de la región es fundamentalmente agropecuaria y el modelo económico que ha prevalecido está basado en la ganadería extensiva (el 65,5\% del área es pasto con 1.3 cabezas de ganado por hectárea) reduciéndose la producción campesina. El departamento es rico en suelos de buena calidad y aguas, tiene 124 kilómetros de playa, planicies y tres serranías que lo recorren de sur a norte, con yacimientos de ferroníquel, carbón y calizas y la mayoría del Parque Nacional Natural Paramillo se encuentra en su jurisdicción. En la figura 1 se muestra la ubicación geográfica del departamento en la Costa Caribe colombiana.

Fecha recepción: 01/05/2007 • Fecha aceptación: 30/05/2007

Dirección de Postal:

Cra. 9 Nro. $9-55$

Montería

Colombia

E-mail:vicnegreteba43@hotmail.com

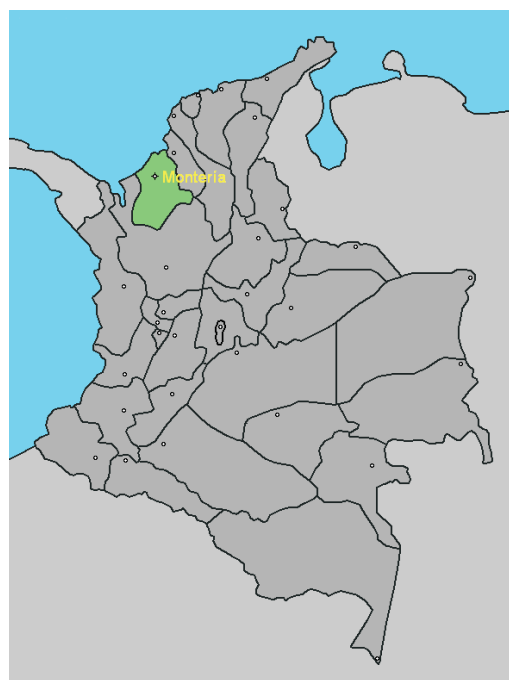

Figura 1. Situación geográfica del departamento de Córdoba en la Costa Caribe Colombiana (extraido de http:/ / www.luventicus.org/ mapas / colombia/ cordoba.btml) 
Desde que Córdoba se constituyó en departamento, hace más de cincuenta años, hasta ahora ha padecido el conflicto armado, con diversos grupos presentes en la zona (Negrete, 2006, 2007; Romero, 1995, 2003). Aunque se han realizado avances importantes en cuanto al proceso de pacificación, dicho conflicto ha producido grandes consecuencias en la región con altos niveles de necesidades básicas insatisfechas, al punto que aproximadamente el 74,1 por ciento de la población es considerada pobre (Negrete, 2001).

A continuación, se señalan otras consecuencias psicosociales y socioeconómicas que ha tenido este conflicto.

\section{POBLACIÓN DESPLAZADA}

La población desplazada ubicada en Córdoba, o personas que han tenido que abandonar sus hogares como consecuencia del conflicto armado, es de 100.000 personas, de estos, 40.000 aproximadamente están localizados en Montería, la capital (Negrete \& Acción Contra el Hambre [ACH], 2002).
Desde 1985, cuando comenzó a llegar un número importante de personas desplazadas a la región, hasta el 2003, ha habido en Montería cerca de 30 invasiones con un gran número de desplazados, invasiones que hoy son consideradas como asentamientos subnormales. De este modo, ocuparon zonas verdes, lotes o predios del gobierno, márgenes del río y antiguos cauces de ciénagas (Negrete, 2001). Durante varios años esta población desbordó la capacidad de algunos servicios públicos (acueducto, energía, recolección de basura, salud, educación) e incrementaron el desempleo y las actividades informales, la inseguridad ciudadana, el riesgo social en niños, adolescentes y jóvenes (prostitución, drogas, enfermedades de transmisión sexual y VIH/SIDA, maternidad a temprana edad y abortos, entre otros). Los municipios reseñados en la Tabla 1 son los que más población desplazada han recibido alcanzando un total de 65.765 (Negrete \& ACH, 2002). El fenómeno del desplazamiento ha sido de tal envergadura que en todas las cabeceras municipales y muchos corregimientos los desplazados han montado sus ranchos o "cambuches" (Lozano, 2003).

Tabla 1. Principales municipios receptores de población desplazada

\begin{tabular}{|c|c|c|c|c|c|c|c|}
\hline Municipios/años & 2001 & 2002 & 2003 & 2004 & 2005 & 2006 & $\begin{array}{c}\text { Población } \\
\text { total * }\end{array}$ \\
\hline Montería & 4.876 & 5.025 & 1.625 & 820 & 1.025 & 1.033 & 22.137 \\
\hline Tierralta & 4.074 & 4.505 & 1.377 & 53 & 130 & 116 & 14.838 \\
\hline Montelíbano & 3.816 & 4.192 & 529 & 540 & 620 & 447 & 12.130 \\
\hline Puerto Libertador & 1.441 & 1.887 & 565 & 482 & 1.000 & 633 & 6.917 \\
\hline Valencia & 1.155 & 2.636 & 122 & 426 & 630 & 390 & 5.878 \\
\hline Planeta Rica & 766 & 355 & 105 & 46 & 152 & 299 & 2.035 \\
\hline Cereté & 499 & 1.131 & 40 & 11 & 35 & 94 & 1.830 \\
\hline TOTAL & & & & & & & 65.765 \\
\hline
\end{tabular}

* Incluye los años anteriores.

De acuerdo con la Red de Solidaridad Social (s.f.), el organismo encargado de atender esta población, de Córdoba salieron en 2005 unas 5803 personas desplazadas y en 2006, unas 6477, es decir hubo un incremento del 12\% (Vicepresidencia de la República, s.f.). Estas personas se dirigieron a diferentes destinos, en la Tabla 2 se muestran algunos de estos destinos. El número de desplazados internos en el departamento, es decir, los que se movilizan entre distintos municipios, es de 44.493 (Negrete \& ACH, 2002). 
Tabla 2. Principales departamentos y distritos receptores de desplazados de Córdoba

\begin{tabular}{lccccccc}
\hline Departamentos/años & $\mathbf{2 0 0 1}$ & $\mathbf{2 0 0 2}$ & $\mathbf{2 0 0 3}$ & $\mathbf{2 0 0 4}$ & $\mathbf{2 0 0 5}$ & $\mathbf{2 0 0 6}$ & $\begin{array}{c}\text { Población } \\
\text { total * }\end{array}$ \\
& & & & & & & \\
\hline Antioquia & 1.126 & 742 & 180 & 176 & 242 & 40 & $9.228^{* *}$ \\
Sucre & 1.726 & 1.704 & 269 & 283 & 585 & 191 & 5.271 \\
Bolívar & 633 & 1.025 & 361 & 255 & 405 & 132 & 3.405 \\
Atlántico & 421 & 458 & 238 & 210 & 286 & 43 & 2.116 \\
Guajira & 223 & 175 & 129 & 56 & 35 & 27 & 904 \\
Bogotá & 95 & 86 & 81 & 110 & 164 & 161 & 891 \\
\hline
\end{tabular}

* Incluye los años anteriores

** Principalmente al Urabá antioqueño y bajo Cauca.

\section{HOMICIDIOS}

Se ha indicado que en Córdoba los homicidios pasaron de 173 en 2005 a 253 en 2006 , es decir que aumentaron $46 \%$, con alzas importantes en Montería, Montelibano, Tierralta, Sahagún y Pueblo Nuevo (Fundación Seguridad y Democracia, s.f.). La Policía enfatiza que las venganzas, riñas y otros, son las principales causas de los homicidios y señala a Montería, Lorica, Sahagún y Cereté como las poblaciones donde se cometen más delitos de esta clase (Bechara, 2005). El incremento en los mismos afecta también a municipios como Cereté, Planeta Rica y Sahagún.

No obstante, se han dado a conocer cifras sobre el "sicariato", o personas que asesinan a otras a cambio de dinero, ligeramente esperanzadoras; así, en el 2004, el 72\% de los homicidios fue cometido por sicarios; en el 2005, el 65\% y en el 2006 , el 45\%, lo que señala una reducción progresiva.

\section{LA CONCENTRACIÓN DE LA TIERRA \\ Y LA ECONOMÍA EN EL DEPARTAMENTO DE CÓRDOBA}

La tenencia y concentración de la tierra, ha sido factor de conflicto en el departamento de Córdoba desde hace más de cien años. El INCORA, en los 40 años que permaneció en Córdoba (1963-2003), adjudicó 134.174 hectáreas a 9.177 familias, el 68,9\% de la tierra adquirida fue entregada al 57\% de las familias en los municipios de conflicto armado y de movimientos campesinos e indígenas. Desde 1987 en adelante, en los municipios del sur de la región, San Jorge y Canalete, el $70 \%$ de los beneficiarios abandonaron las tierras por amenazas o temor al conflicto, y desde 1995, se comenzaron a comprar tierras aledañas a Montería por encima del valor comercial, creando desde entonces distorsión en el mercado (Negrete, 2007); la Tabla 3 enumera los municipios donde se realizaron adjudicaciones de tierras (Negrete, Galeano, \& Berrocal, 1998; Negrete, Rodríguez, Uribe, \& Pachón, 1999).

Tabla 3. Adjudicación de tierras en diferentes municipios con conflicto.

\begin{tabular}{lcc}
\hline \multicolumn{1}{c}{ Municipios } & Hectáreas & Familias \\
\hline Canalete & 2.512 .2 & 193 \\
Montelíbano & 12.697 .4 & 707 \\
Montería & 21.698 .6 & 1.583 \\
Puerto Libertador & 2.864 .0 & 227 \\
Tierralta & 9.751 .5 & 592 \\
Valencia & 10.831 .3 & 641 \\
Planeta Rica & 4.122 .6 & 198 \\
Ayapel & 10.781 .9 & 576 \\
Pueblo Nuevo & 12.147 .5 & 517 \\
San Andrés de Sotavento & 5.055 .8 & Indígenas \\
TOTAL & $92.462 .0(68.9 \%)$ & $5.234(57 \%)$
\end{tabular}


El Instituto Geográfico “Agustín Codazzi” nos corrobora el fenómeno de la concentración de la tierra: el 77,1\% de los predios menores de 20 hectáreas ocupan el 15,7\% de la superficie; el 18,2\% de los predios entre 20 y 100 hectáreas ocupan el $33,3 \%$ de la superficie y el $4,5 \%$ de los predios mayores de 100 hectáreas ocupan el 51\% de la superficie.

\section{Lospredios abandonadosy las autorizaciones de venta}

En el INCORA, antes de desaparecer recibieron 2.948 solicitudes de familias desplazadas aspirantes a subsidios de tierra, de estas familias (969), el 32,8\%, aseguran haber dejado 38.738 hectáreas abandonadas tanto en Córdoba, la mayoría, como en las áreas del Urabá antioqueño y chocoano. En dichas familias, figuran 262 mujeres como jefe de hogar y solo 33 del total tienen escritura o resolución de propiedad (Negrete, 2006). El INCODER, el reemplazo del INCORA, fue creado en Mayo del 2003 y, desde que empezó a trabajar formalmente, le han solicitado la expedición de más de 3.000 autorizaciones de ventas de parcelas (Negrete, 2007). Sin embargo, para recibir la autorización, el beneficiario debe estar sin deudas de ninguna clase con el Instituto, algo muy poco frecuente, lo que indica que dichas solicitudes se han podido realizar bajo ciertas presiones.

\section{ECONOMÍA}

Desde hace cinco años, la ciudad de Montería tiene un crecimiento económico importante, dentro de su escaso desarrollo por debajo del promedio nacional, surgiendo diferentes explicaciones sobre este hecho; de las trece ciudades que conforman la muestra del Departamento Administrativo Nacional de Estadística (DANE), las que registraron crecimientos por encima del promedio mensual $(0,3 \%)$, fueron Pereira $(0,82 \%)$, Cartagena $(0,81 \%)$, Manizales $(0,75 \%)$, Barranquilla (0,74\%), Medellín (0,35\%) y Cali $(0,33 \%)$, y por debajo del promedio mensual se situaron Neiva $(0,28 \%)$, Cúcuta $(0,24 \%)$, Bucaramanga $(0,22 \%)$, Bogotá, D.C. $(0,17 \%)$, Montería (0,11\%), Villavicencio (0,08\%) y Pasto $(-0,24 \%)$ (ASOBANCARIA, 2007, 5 de junio).

Sin embargo, este crecimiento resultaba sorprendente y la revista Semana (27 de Septiembre de 2004) indicaba en una crónica que era difícil precisar qué actividad económica originaba esta bonanza. Los informes del Banco de la República y el (DANE) de los años 2005, 2006 y del primer trimestre del 2007, aportan alguna información a este respecto (Tabla 4).

Tabla 4. Captaciones y créditos bancarios de la costa caribe. Años 2001-2006 (junio 30). Miles de pesos

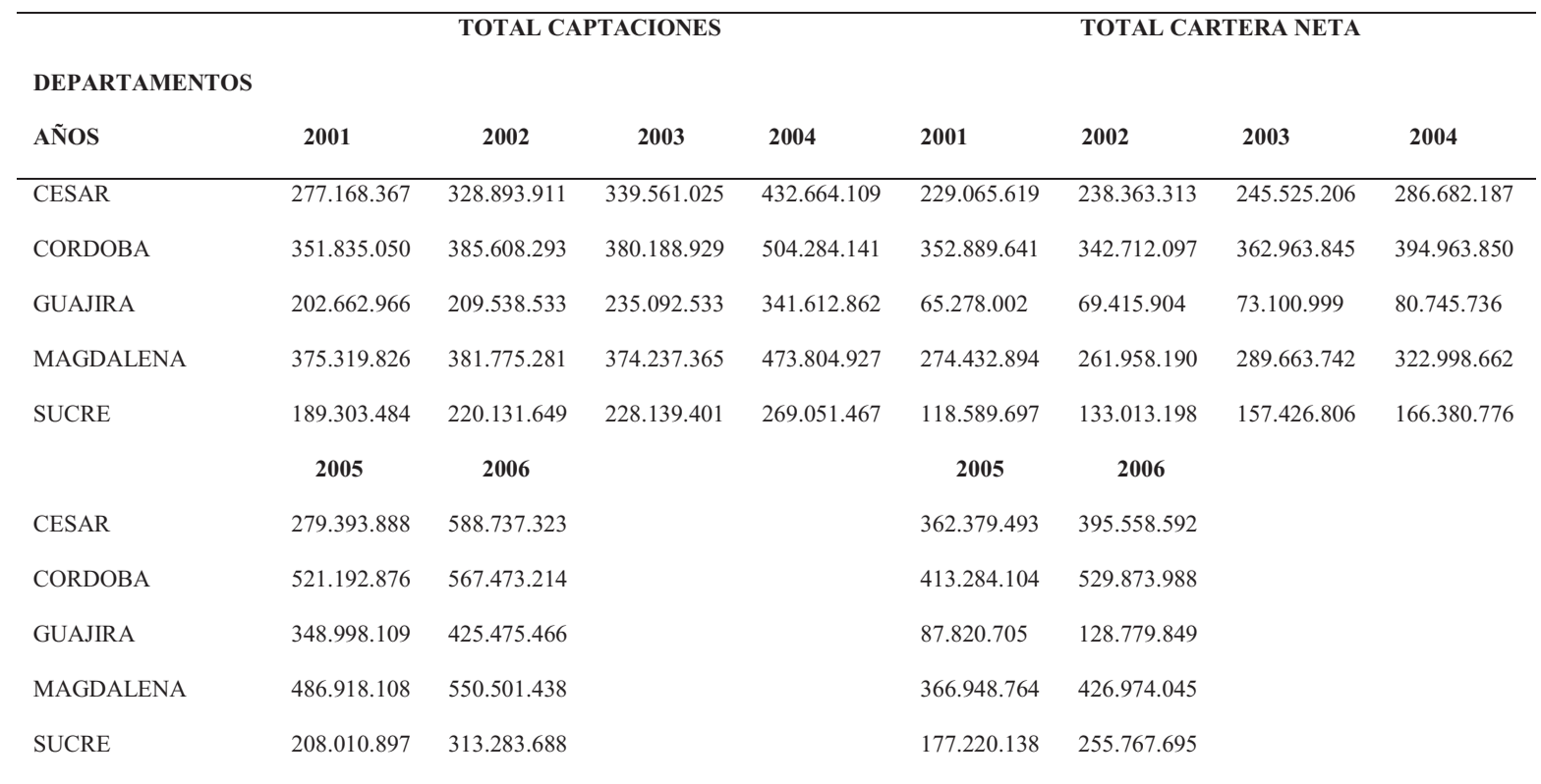

Según los datos de la tabla, Córdoba tiene el mayor volumen en las captaciones y la utilización del crédito en el sistema bancario, de los cinco departamentos de la costa Caribe colombiana con más similitud, por lo que surge la pregunta, ¿de qué actividad económica provienen dichos recursos? Aunque una gran parte de la economía que se mueve en el departamento, y la que es captada por los bancos, tiene su base en la agricultura, ganadería y minería, los aportes que hacen estas actividades no alcanzan a justificar las proporciones señaladas.

\section{Nuevas inversiones}

En Montería están interviniendo empresas y asociaciones de distintos lugares del país, en especial de Medellín, Cali, Bogotá 
y Santander (Negrete, 2007), y al parecer estas inversiones se han dirigido al comercio, tierra, ganado, madera y cultivos agroindustriales, y el progreso que vive la ciudad en los últimos años se debe al incremento de captaciones en el sistema financiero, las inversiones vía crédito bancario efectuadas en el comercio y la vivienda de estratos medio y alto, las obras de infraestructura de las administraciones gubernamentales y el mantenimiento de su economía tradicional basada en la agricultura, ganadería, minería y una incipiente manufactura (Negrete, 2006).

De este modo, de acuerdo con los datos citados, y las apreciaciones de los analistas, es por el sistema financiero y las nuevas inversiones por donde pueden filtrarse recursos de procedencia no identificada.

\section{Cultivos de uso ilícito}

Al despuntar la década de los años ochenta el tráfico de sustancias ilegales estaba en constante crecimiento en el país y las grandes organizaciones se fijaron en Córdoba por sus características naturales: 124 kilómetros de litoral, las serranías de Abibe, San Jerónimo y Ayapel, extensas llanuras; la cercanía a Panamá, el Parque Nacional Natural Paramillo con 360.000 hectáreas en el sur del departamento y el aislamiento geográfico (Negrete, 2006; Romero, 2003; Sánchez, 2001). Estos grupos estaban situados en Montería, Canalete, Cereté, Montelíbano, Buenavista y la zona costanera, donde fue frecuente el empleo de embarcaciones rápidas por el mar; por otra parte, hubo períodos en que el número de pistas de aterrizaje en operación superaba las 30 (Sánchez, 2001). En el año 1993, en el recorrido que hicimos un grupo de ambientalistas interesados en conocer la situación del río San Jorge, nos topamos con varias personas movilizando insumos para el procesamiento de sustancias ilegales, parece ser que en Córdoba comenzaban los cultivos de uso ilícito; años después se extenderían a los municipios de Tierralta, Valencia y Ayapel (Villaraga \& Plazas, 1993).

Estas actividades se han centrado en sitios claves del Parque Nacional Natural Paramillo, con 460.000 hectáreas en jurisdicción de los municipios de Tierralta, Montelíbano y Puerto Libertador, en Córdoba, e Ituango, Peque y Dabeiba en Antioquia y en sus alrededores. Ante semejante tamaño, el área sembrada es difícil de precisar, tal vez por esta razón los datos oficiales fluctúan entre 7.000 y 14.000 hectáreas. Bajo la influencia de estas actividades, se ha incrementado notoriamente la inseguridad en la zona y se han modificado la visión, la cultura, los modos productivos de la zona y la convivencia con la ilegalidad en todas sus formas.

Desde el año 2004, el gobierno adelanta programas de erradicación por aspersión y manuales, en este último participan 500 personas desmovilizadas, y hasta el mes de mayo del 2007 habían erradicado 3.148 hectáreas.

\section{EXPRESIONES DEL REARME}

Parece inevitable que ciertos grupos armados que habían abandonado las armas, es decir se habían desmovilizado, sufran un proceso de renovación ya que son una estructura de protección; de este modo, algunos grupos ya se han reconstruido y comienzan a reclutar a otros desmovilizados (Fundación Ideas para la Paz, 2005, Agosto 12). En el octavo informe de la Misión de Apoyo al Proceso de Paz en Colombia (MAPP, OEA), se señala que se han observado situaciones de posibles rearmes, reductos no desmovilizados y la aparición de otros grupos armados (Programa de las Naciones Unidas para el Desarrollo, 2007). Frank Pearl reconoce que la principal amenaza para la reinserción es precisamente el nuevo reclutamiento, ya que entre el 3 y el 5\% de quienes se desmovilizan vuelve a rearmarse, fenómeno que ha ocurrido en muchos lugares del mundo, aunque esto no constituye la actuación de la mayoría, y no explica los niveles de criminalidad (Programa de las Naciones Unidas para el Desarrollo, 2007).

En Córdoba sólo un 30\% aproximadamente de anteriores grupos desmovilizados aprovechó las ventajas de la reincorporación y su reinserción la podemos considerar exitosa; un número no determinado ingresaron a otros grupos, mientras otros perdieron la vida por diferentes motivos (Bechara, 2005). Además, se están reclutando jóvenes en los asentamientos subnormales y barrios populares de Montería, en los municipios de Planeta Rica y Buenavista algunos desmovilizados prestan servicio de vigilancia en las haciendas; en los municipios de Moñitos y Los Córdobas, existe presencia, aunque sin confirmar, de hombres armados y la Misión de de la OEA, menciona en sus informes la existencia de una estructura armada entre los municipios de Montelíbano y Puerto Libertador, con participación de población desmovilizada, otra en los municipios de Valencia y Tierralta, que al parecer no participó en la desmovilización, y otra sin verificar en Tierradentro (Montelíbano).

Ante todo esto surgen las siguientes preguntas: ¿cuál es la situación de los desmovilizados?, ¿Por qué algunos individuos han vuelto a estos grupos armados?

\section{La situación de los desmovilizados}

Córdoba fue, y al parecer sigue siendo, un proveedor de hombres para los grupos armados; esto es debido a la pobreza, la falta de oportunidades, los conflictos intrafamiliares y las venganzas (Negrete, 2007) y, de este modo, 3705 cordobeses formaron parte de los grupos armados en diferentes partes del país. La gran mayoría de los combatientes tenían edades entre los 21 y 40 años, lo que representaba el 89\% del total, con 3485 hombres y 220 mujeres; aunque el número de mujeres es reducido respecto al de los hombres, no deja de llamar la atención su número en un departamento como Córdoba, que no tenía referencia en este sentido. 
En cuanto a los municipios con más desmovilizados, en Montería, Tierralta y Valencia residían 3.005 de los 3.075, esto es debido al alto número de jóvenes sin oportunidades en Montería y al control riguroso de algunos grupos armados en Tierralta y Valencia. La mayoría de los combatientes, el 78\% aproximadamente, eran de los estratos bajos de estas poblaciones, jóvenes que no estudiaban o habían terminado el bachillerato pero sin opción para continuar sus estudios, estaban desempleados y trabajaban ocasionalmente en actividades informales. Los de origen campesino desempeñaban labores de jornaleros, vaqueros o ayudaban a los padres en oficios agropecuarios. Además, del bajo nivel de formación académica y laboral, esta población no recibió acompañamiento psicosocial personal ni familiar de ningún otro tipo. Otro elemento que tampoco ayuda a la superación de esta situación es la falta de proyectos productivos urbanos y el fracaso de algunos del área rural.

Para detectar los progresos y las fallas, la Alta Consejería ha iniciado la descentralización y el seguimiento individualizado que incluye un psicólogo y trabajador social por cada 150 desmovilizados. (Programa de las Naciones Unidas para el Desarrollo, 2007). Generar empleo y lograr proyectos productivos exitosos han sido algunos de los principales problemas que han enfrentado los ex combatientes, aun cuando se han desarrollado programas para que elaboren por sí mismos alternativas económicas sostenibles; no obstante, en la formación académica se ha atendido al 25,9\% de los desmovilizados; en la en formación ocupacional al 72,2\% y en proyectos productivos sólo al 37,8\% (Programa de las Naciones Unidas para el Desarrollo, 2007).

\section{LA ZONA DE UBICACIÓN}

La Zona de Ubicación tiene un área de 368 kilómetros cuadrados, y se define así porque fue la zona designada para iniciar conversaciones entre el gobierno y los grupos armados. La conforman seis corregimientos y 46 veredas, y contaba con 8.643 habitantes y 1.714 viviendas aproximadamente. Las familias que habitan el área han pasado durante los últimos 30 años por diferentes formas de vida impuestas por el aislamiento y el abandono (1975-1984), el conflicto armado (1985-1991) y el control de los grupos armados (1991-2005) (Negrete, 2003). Este proceso ha hecho que las infraestructuras estén en unas condiciones muy deterioradas, las vías de acceso están en malas condiciones, hay dificultades para acceder a los servicios de salud, pocas viviendas cuentan con letrinas o pozos sépticos, el agua para consumo la toman de jagüeyes y solo el 50\% de la población cuenta con el servicio de energía eléctrica (Negrete, 2007). Además, el jornal-día volvió a reducirse mucho y no es fácil conseguirlo (Negrete, 2007). Aunque se esperaba que los cursos de capacitación dictados por el Servicio Nacional de Aprendizaje (SENA) solventaran la situación social y económica, no se conocen proyectos ni organizaciones ni negocios creados, esto ha hecho que la desnutrición de los niños llegue al 70\%. La situación se ve agravada por la existencia de niños y niña sin reconocimiento de paternidad ni apoyo económico para su manutención, y por el modelo por el que se han decidido muchos adolescentes y jóvenes: la indumentaria, el vocabulario, el peinado y los ademanes generan la ilusión de pertenecer a algún grupo armado.

El Fondo de las Naciones Unidas para la infancia (UNICEF) opera en la zona desde el año 2004, con un programa para la recuperación psicoafectiva de los niños, el cual comprende educación, salud y acompañamiento psicológico, el total aproximado de niños atendidos es de 1.200.

\section{CONCLUSIONES}

Esta recopilación de información que he presentado, muestra algunas de las consecuencias y problemáticas existentes en la región, y se constituye para nosotros en un punto de partida para impulsar alternativas comprometidas con el desarrollo, la inclusión social y la convivencia. Para tal fin es necesario, el concurso de diferentes sectores sociales y académicos, así como el análisis detenido de una situación social, que es sin duda compleja, pero ante la cual existen posibles soluciones. El desarrollo de programas, la generación de nuevas oportunidades, el cambio en las actitudes hacia la convivencia con el conflicto, la atención psicológica y psicosocial a las víctimas del conflicto, incluso la modificación de ciertas costumbres y hábitos fuertemente arraigados, así como otros muchos aspectos, requieren atención inmediata.

\section{REFERENCIAS}

ASOBANCARIA. (2007, 5 de junio). Principales indicadores entre el 28 de mayo y el 5 de junio. Informe Semanal de Indicadores. Bogotá: Autor.

Bechara, E. (2005). Documentos para la Reflexión. Distintos Aspectos Sobre el Proceso de Negociación Gobierno- AUC. Montería: Universidad del Sinú.

Fundación Ideas para la Paz (2005, agosto 12). Siguiendo el conflicto: hechos y análisis de la semana. Recuperado el 10 de junio de 2007, de http: www.ideaspaz.org/publicaciones.

Fundación Seguridad y Democracia (s.f.). Balance de Seguridad 2006. Recuperado el 10 de junio de 2007 de http//info@seguridadydemocracia.org

Lozano, F. (2003). Las Otras Córdoba. Dignidad más allá del sometimiento. Bogotá: Informe elaborado para la Mesa de Córdoba por la paz.

Negrete, V. \& Acción Contra el hambre [ACH], (2002). El desplazamiento por la violencia en el departamento de Córdoba. 1999-2001. Montería, Colombia: ACH.

Negrete, V. (2001). El Proceso de Reubicación de Población Desplazada por la Violencia en Predios Rurales del Municipio de Montería. Montería, Colombia: Alto Comisionado de las Naciones Unidas para los Refugiados (ACNUR).

Negrete, V. (2003). Jóvenes, familia y sociedad. De la exclusión al riesgo. El caso Córdoba. Montería: Universidad.

Negrete, V. (2006). Documentos para la reflexión 1: El proceso de negociación gobierno-AUC. Montería: Universidad del Sinú. 
Negrete, V. (2007). Documentospara la Reflexión 2. Grupos Políticos, Iglesias y conflicto armado. Montería: Universidad del Sinú.

Negrete, V., Galeano, J., \& Berrocal, I. (1998). Urabá, conflictosy educación rural. Montería: Universidad del Sinú.

Negrete, V., Rodríguez, P., Uribe, J., \& Pachón, M. A. (1999). Grupos de desplazados. Encuentro con Tierralta. Montería: Universidad del Sinú.

Programa de las Naciones Unidas para el Desarrollo (2007). La reinserción en las regiones: todo un desafío. Hechos del Callejón, 25, 1-20.

Romero, M. (1995). Transformación rural, violencia política y narcotráfico en Córdoba 1953-1991. Serie controversia, 167.
Romero, M. (2003). Paramilitarismo y Autodefensas, 1982-2003. Bogotá: Universidad Nacional.

Sánchez, A. J. (2001). Las crónicas que no me dejaban contar. Montería: Autor.

Vicepresidencia de la República (s.f.). Desplazamiento Forzado Folleto]. Recuperado el 10 de junio de 2007, de http://www.derechoshumanos.gov.co/observatorio/ indicadores/2004/noviembre/desplazamientonov.pdf

Villaraga, A., \& Plazas, N. (1993). Para reconstruir los sueños. Bogotá: Fundación Progresar. 